\title{
Internal brand management: introduction to the special issue and directions for future research
}

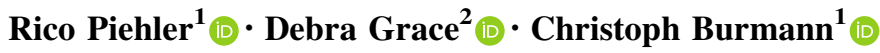

Published online: 2 February 2018

(C) Macmillan Publishers Ltd., part of Springer Nature 2018

\begin{abstract}
This special issue of the Journal of Brand Management has been developed in consideration of the existing gap between the relevance of and research attention to internal brand management (IBM). Despite its relevance, research dealing with brand management in the context of internal stakeholders is still limited. Therefore, we identify five directions for future research after an introduction to the topic. Future research should (1) validate the relevance of IBM, (2) increase the generalizability of IBM research findings, (3) deepen and (4) broaden the IBM framework, and (5) extend methodologies in IBM research. This special issue addresses some of the identified areas for future research by including five articles covering a variety of IBM topics. It is our hope this special issue advances IBM research and encourages researchers to start and continue engaging in research in this important area.
\end{abstract}

Rico Piehler

rico.piehler@uni-bremen.de;

http://www.lim.uni-bremen.de

Debra Grace

d.grace@griffith.edu.au;

https://www.griffith.edu.au/business-government/griffith-

business-school/departments/department-marketing

Christoph Burmann

burmann@uni-bremen.de;

http://www.lim.uni-bremen.de

1 Chair of Innovative Brand Management, Faculty of Business Studies and Economics, University of Bremen, Hochschulring 4, 28359 Bremen, Germany

2 Department of Marketing, Griffith Business School, Griffith University, Parklands Drive, Gold Coast QLD 4222, Australia
Keywords Internal brand management · Employees · Research directions

\section{Introduction}

An important brand-related task of organizations is the development of a bundle of functional and non-functional benefits that differentiate an organization's offering from that of competitors and its communication, in the form of a brand promise, to external stakeholders, such as consumers. A more difficult but crucial brand-related function of organizations is the fulfilment of the brand promise through the delivery of the communicated benefits. Ultimately, this delivery is the responsibility of internal stakeholders, such as employees, either directly through their behaviour towards external stakeholders, such as customers, or indirectly through their behaviour towards other internal stakeholders. As such, they are strategically important to brand management success.

Despite the intuitive appeal of managing the brand internally and the growing body of practitioner interest and investment in such a strategy, there is a paucity of conceptual and empirical papers addressing this important issue. In comparison with the vast amount of research dedicated to brand management in the context of external stakeholders, research dealing with brand management in the context of internal stakeholders, i.e. internal brand management (IBM), is still limited. Nevertheless, it is necessary to complement the outside-in perspective (i.e. external orientation: market and customers) by the insideout perspective (i.e. internal orientation: organization and employees) in line with the competence-based view of the firm. 


\section{Directions for future research}

As guest editors of this special issue of the Journal of Brand Management, we would like to bring research attention to this important topic by identifying directions for future research based on a literature review of IBM research in the past decade. We identified five overarching areas for future research.

The first area is related to validating the relevance of IBM for brand management and company success. Therefore, future research should hypothesize and empirically investigate the effects of IBM on organizational performance outcomes, for example, customer-related outcomes (e.g. customer satisfaction, brand attachment, brand strength, customer-based brand equity) and financial performance (e.g. turnovers, profits, shareholder value) (Baumgarth and Schmidt 2010; Burmann et al. 2009; Kimpakorn and Tocquer 2009; King and Grace 2009; Piehler et al. 2016; Sirianni et al. 2013; Tuominen et al. 2016).

The second area for future research is to increase the generalizability of research findings. Previous empirical IBM studies often focus on single organizations (e.g. Baker et al. 2014; Matanda and Ndubisi 2013; Porricelli et al. 2014), industries, especially service-based industries like the financial service (e.g. du Preez and Bendixen 2015; Löhndorf and Diamantopoulos 2014) or tourism and hospitality industry (e.g. Kimpakorn and Tocquer 2009; King 2010; Punjaisri and Wilson 2011), and specific countries (e.g. Baumgarth and Schmidt 2010; Kimpakorn and Tocquer 2010; Nyadzayo et al. 2015). Such focus limits the generalizability of the results; therefore, future research should investigate previously identified relationships in different organizations, industries (e.g. service-based vs non-service-based, B2B vs B2C), and countries, i.e. investigating country- and culture-specific effects (Burmann et al. 2009; Chang et al. 2012; Hughes 2013; King and Grace 2009, 2010; Nyadzayo et al. 2016; Piehler et al. 2016; Punjaisri et al. 2008, 2009; Sirianni et al. 2013; Terglav et al. 2016). Covering multiple organizations, industries and countries might help to uncover general relationships and organization-, industry- or country/culture-specific relationships.

The third area for future research is to deepen the IBM framework by gaining more insights into employee-related IBM outcomes, managerial instruments to affect these outcomes, and moderators that affect relationships between outcomes and between managerial instruments and outcomes. Regarding employee-related IBM outcomes, recent research highlights the affective dimensions of commitment (King 2010; King and Grace 2010; Punjaisri and Wilson 2011) and identification (Piehler et al. 2016) and multidimensional perspectives for brand understanding/knowledge (Xiong et al. 2013; Piehler et al. 2016) and brand-related behaviour (Burmann and Zeplin 2005; Burmann et al. 2009; Shaari et al. 2011; Chang et al. 2012; Porricelli et al. 2014; Nyadzayo et al. 2015, 2016; Piehler et al. 2015, 2016). Future research should continue to develop the dimensionality of these IBM outcomes and deliver further empirical validation (Burmann et al. 2009; Terglav et al. 2016). In addition, future research should explore the relationships between these dimensions (Piehler et al. 2016). To expand knowledge about managerial instruments, previous IBM research calls for a more detailed investigation of specific instruments of brand-oriented human resource management, leadership, internal communication, and external communication that potentially affect employee-related IBM outcomes (Baker et al. 2014; Baumgarth and Schmidt 2010; Henkel et al. 2007; Kimpakorn and Tocquer 2010; Löhndorf and Diamantopoulos 2014; Piehler et al. 2016; Xiong et al. 2013). Finally, to better understand the relationships between employee-related IBM outcomes and between managerial instruments and outcomes, future research should consider moderators of these relationships (Baumgarth and Schmidt 2010; Hughes 2013; Punjaisri et al. 2008). Suggested moderators include employee characteristics (Piehler et al. 2016), such as gender (King 2010; King and Grace 2012; Matanda and Ndubisi 2013) and skills and abilities (Baker et al. 2014). Other suggested moderators include organizational characteristics (Baker et al. 2014; Burmann et al.,2009; King and Grace 2009; Piehler et al. 2016), such as organizational structure (flat vs hierarchal; modern vs traditional), organizational climate or culture, company size (small vs large), and ownership status (publicly owned vs privately owned).

The fourth area for future research is to broaden the IBM framework by considering brand portfolios and other stakeholders (e.g. external partners). While the corporate brand is usually the focus of IBM research, in practice, many organizations operate with multiple brands. Brand portfolios increase the degree of complexity for IBM, and future research should shed light on this rarely investigated topic (Baker et al. 2014; Baumgarth and Schmidt 2010; Burmann et al. 2009; Hughes 2013). Another area to broaden the IBM framework is to consider other stakeholders, such as external partners (e.g. suppliers, distribution partners, call centres). As brand value is often cocreated by multiple stakeholders, who interact with each other and with customers, future research should integrate these stakeholders into the IBM framework (Burmann et al. 2009; Dean et al. 2016; Saleem and Iglesias 2016). While some investigations of IBM in the franchising context exist (Merrilees and Frazer, 2013; Nyadzayo et al. 2015, 2016), aligning the behaviour of external partners and their 
employees in less constrained and less formal relationships remains to be explored in future research (Saleem and Iglesias 2016).

Finally, the fifth area for future research is related to extending methodologies by using multiple data sources and longitudinal or experimental study designs. Many empirical IBM studies apply employee self-reports as source of measures. Therefore, calls for using other sources of measures, such as management, supervisor, colleague, subordinate, or customer evaluations as well as objective measures and data, have been articulated (Baumgarth and Schmidt 2010; Piehler et al. 2016; Terglav et al. 2016). Complementing employee self-evaluations with other measures would not only provide further insights into the relationships but also help to reduce common method effects. In addition, empirical IBM research often applies a cross-sectional study design. Such designs do not allow to assess hypothesized causalities; therefore, future research should apply longitudinal or experimental study designs (Baumgarth and Schmidt 2010; Chang et al. 2012; Hughes 2013; Löhndorf and Diamantopoulos 2014; Matanda and Ndubisi 2013; Piehler et al. 2016; Punjaisri and Wilson 2011; Tuominen et al. 2016).

\section{Special issue on internal brand management}

By including five articles in this special issue, we, as guest editors, would like to address some of the identified areas for future research. The Journal of Brand Management represents the ideal publication outlet for this special issue as several important contributions to IBM research have been published in the journal (Burmann and Zeplin 2005; Burmann et al. 2009; Gapp and Merrilees 2006; Harris 2007; Ind 2003; Ind and Bjerke 2007; Kimpakorn and Tocquer 2009; King and Grace 2008; King et al. 2012; Punjaisri and Wilson 2007; Tuominen et al. 2016). With Ind and Bjerke (2007), Harris (2007), King and Grace (2008), and Punjaisri and Wilson (2007), four articles that deal with employees in an IBM context of are among the Top 20 articles published in the Journal of Brand Management in 1993-2014 based on downloads from 2009 to 2014 (Powell 2014). With Mosley (2007) and Moroko and Uncles (2008), two more articles among the Top 20 are related to (prospective) employees in the context of employer branding. Overall, six of the Top 20 most downloaded articles in the Journal of Brand Management address the topic of (prospective) employees as a target group for brand management, thus indicating relevance for the research community.

The opening article by Pramod Iyer, Arezoo Davari, and Audhesh Paswan entitled "Determinants of brand performance: the role of internal branding" addresses the call for future research regarding the relevance of IBM by empirically investigating the effect of IBM, brand orientation, and strategic brand management on brand performance. Survey data from 218 brand/marketing managers reveal that while brand orientation, strategic brand management, and IBM are directly associated with brand performance, IBM partially mediates the effect of brand orientation and strategic brand management on brand performance. The results highlight the need for organizations to cultivate IBM as it delivers further empirical evidence for the role of employees in improving a brand's performance.

The second article entitled "Employees' brand understanding, brand commitment, and brand citizenship behaviour: a closer look at the relationships among construct dimensions" by Rico Piehler responds to the call for future research to deepen the IBM framework by gaining more insights into employee-related IBM outcomes. The article investigates the links among the IBM outcomes of brand understanding, brand commitment, and brand citizenship behaviour, at both higher-order and lower-order levels. Using a sample of 790 employees from a German tourism company, the study reveals the relevance of the brand understanding dimension of behaviour relevance (i.e. employees' understanding that they contribute to the brand's success) as it affects brand commitment and all dimensions of brand citizenship behaviour. Other dimensions of brand understanding and brand commitment only seem to be of relevance for certain brand citizenship behaviour dimensions. The article contributes to IBM research by providing a closer analysis of the dimensions of different IBM outcome constructs and their relationships.

In the third article entitled "Brand signalling: an antecedent of employee brand understanding" Emma Karanges, Kim A. Johnston, Ian Lings, and Amanda T. Beatson deepen the IBM framework by gaining more insights into managerial instruments to affect employeerelated IBM outcomes. They develop a conceptual model of brand signalling antecedents to brand understanding, namely brand signal quality, brand signallers, and brand signal channels. The relationships represented within the conceptual model infer that employees' perception of brand signal quality, their perceptions of the form and transmission of brand signalling channels used to transmit brand signals, and their perceptions of the signaller's competences, qualities, and style responsible for transmitting the brand signal positively affects their brand understanding. The conceptual model benefits organizations by describing the role that brand signalling plays in communicating the brand promise and elevates the importance of employee understanding of the brand to fulfil the promise.

In the fourth article entitled "Strengthening internal brand equity with brand ambassador programs: 
development and testing of a success factor model" Holger J. Schmidt and Carsten Baumgarth identify success factors of a brand ambassador program (BAP). This research thereby also deepens the IBM framework by gaining more insights into managerial instruments to affect employeerelated IBM outcomes. The authors develop a conceptual BAP framework and a list of potential success factors. They use a longitudinal case study from the service industry to test and adapt their success factor model. The results reveal that a BAP is not an isolated IBM instrument and that brand orientation, brand management, and C-level support affect its impact. The study also indicates that a BAP is a dynamic and phase-oriented approach and that the success of a BAP is based on a combination of the specific characteristics of the coordinator, the program design, the brand ambassadors, and the target groups. The updated BAP success factor model contains 31 factors and provides a holistic overview of the necessary steps to implement a BAP.

The fifth and final article entitled "Sponsorship as an internal branding tool and its effects on employees' identification with the brand" by Katharina M. Hofer and Reinhard Grohs also deepens the IBM framework by gaining more insights into managerial instruments to affect employee-related IBM outcomes. The authors investigate how employees' perceptions of sponsorship characteristics impact their identification with the brand. Using a sample of 165 employees of an Austrian producer of baking ingredients that sponsors the Austrian national biathlon team, the results reveal that employees' general perceptions of their employer's sponsorship (i.e. general attitude towards sponsorship) strongly affect employees' brand identification while their perceptions of the specific sponsorship (i.e. attitude towards the sponsored property and perceived fit) do not affect their brand identification. Consequently, this study confirms the necessity to consider employees as a target group of external communication.

\footnotetext{
Acknowledgements As guest editors, we wish to thank everyone who submitted manuscripts for this special issue. We would like to congratulate the authors whose articles have been accepted. At the same time, we are aware that we were not able to include many submitted manuscripts in this special issue. We strongly encourage those authors to continue their research, and we hope that the reviewers' and guest editors' feedback helped to develop and improve all submitted manuscripts. At this point, we would like to thank our expert team of reviewers for their helpful feedback and advice to the authors and their support through several rounds of reviews. We are aware that in the relatively small community of IBM researchers reviewing manuscripts for this special issue is time-consuming. Therefore, we are very thankful that many experienced researchers agreed to support the guest editors and guide the authors through the review process. We would also like to thank the journal editors, especially Tim Oliver Brexendorf, for working with us during the past 2 years to make this special issue possible. Likewise, we wish to thank Ceridwyn King as renowned IBM researcher for her advice and
}

support. We hope that this special issue advances IBM research and encourages researchers to start and continue engaging in research in this important area. It has been a pleasure and an honour to serve as guest editors of this special issue. We hope that the readers enjoy our selection of IBM articles!

\section{References}

Baker, T.L., A. Rapp, T. Meyer, and R. Mullins. 2014. The role of brand communications on front line service employee beliefs, behaviors, and performance. Journal of the Academy of Marketing Science 42(6): 642-657.

Baumgarth, C., and M. Schmidt. 2010. How strong is the business-tobusiness brand in the workforce? An empirically-tested model of 'internal brand equity' in a business-to-business setting. Industrial Marketing Management 39(8): 1250-1260.

Burmann, C., and S. Zeplin. 2005. Building brand commitment: A behavioural approach to internal brand management. Journal of Brand Management 12(4): 279-300.

Burmann, C., S. Zeplin, and N. Riley. 2009. Key determinants of internal brand management success: An exploratory empirical analysis. Journal of Brand Management 16(4): 264-284.

Chang, A., H.H. Chiang, and T.S. Han. 2012. A multilevel investigation of relationships among brand-centered HRM, brand psychological ownership, brand citizenship behaviors, and customer satisfaction. European Journal of Marketing 46(5): 626-662.

Dean, D., R.E. Arroyo-Gamez, K. Punjaisri, and C. Pich. 2016. Internal brand co-creation: The experiential brand meaning cycle in higher education. Journal of Business Research 69(8): 3041-3048.

Du Preez, R., and M.T. Bendixen. 2015. The impact of internal brand management on employee job satisfaction, brand commitment and intention to stay. International Journal of Bank Marketing 33(1): 78-91.

Gapp, R., and B. Merrilees. 2006. Important factors to consider when using internal branding as a management strategy: A healthcare case study. Journal of Brand Management 14(1-2): 162-176.

Harris, P. 2007. We the people: The importance of employees in the process of building customer experience. Journal of Brand Management 15(2): 102-114.

Henkel, S., T. Tomczak, M. Heitmann, and A. Herrmann. 2007. Managing brand consistent employee behaviour: Relevance and managerial control of behavioural branding. Journal of Product \& Brand Management 16(5): 310-320.

Hughes, D.E. 2013. This ad's for you: The indirect effect of advertising perceptions on salesperson effort and performance. Journal of the Academy of Marketing Science 41(1): 1-18.

Ind, N. 2003. Inside out: How employees build value. Journal of Brand Management 10(6): 393-402.

Ind, N., and R. Bjerke. 2007. The concept of participatory market orientation: An organisation-wide approach to enhancing brand equity. Journal of Brand Management 15(2): 135-145.

Kimpakorn, N., and G. Tocquer. 2009. Employees' commitment to brands in the service sector: Luxury hotel chains in Thailand. Journal of Brand Management 16(8): 532-544.

Kimpakorn, N., and G. Tocquer. 2010. Service brand equity and employee brand commitment. Journal of Services Marketing 24(5): 378-388.

King, C. 2010. 'One size doesn't fit all': Tourism and hospitality employees' response to internal brand management. International Journal of Contemporary Hospitality Management 22(4): $517-534$. 
King, C., and D. Grace. 2008. Internal branding: Exploring the employee's perspective. Journal of Brand Management 15(5): $358-372$.

King, C., and D. Grace. 2009. Employee-based brand equity: A third perspective. Services Marketing Quarterly 30(2): 122-147.

King, C., and D. Grace. 2010. Building and measuring employeebased brand equity. European Journal of Marketing 44(7/8): 938-971.

King, C., and D. Grace. 2012. Examining the antecedents of positive employee brand-related attitudes and behaviours. European Journal of Marketing 46(3): 469-488.

King, C., D. Grace, and D.C. Funk. 2012. Employee brand equity: Scale development and validation. Journal of Brand Management 19(4): 268-288.

Löhndorf, B., and A. Diamantopoulos. 2014. Internal branding: Social identity and social exchange perspectives on turning employees into brand champions. Journal of Service Research 17(3): 310-325.

Matanda, M.J., and N.O. Ndubisi. 2013. Internal marketing, internal branding, and organisational outcomes: The moderating role of perceived goal congruence. Journal of Marketing Management 29(9/10): 1030-1055.

Merrilees, B., and L. Frazer. 2013. Internal branding: Franchisor leadership as a critical determinant. Journal of Business Research 66(2): 158-164.

Moroko, L., and M.D. Uncles. 2008. Characteristics of successful employer brands. Journal of Brand Management 16(3): 160-175.

Mosley, R.W. 2007. Customer experience, organisational culture and the employer brand. Journal of Brand Management 15(2): 123-134.

Nyadzayo, M.W., M.J. Matanda, and M.T. Ewing. 2015. The impact of franchisor support, brand commitment, brand citizenship behavior, and franchisee experience on franchisee-perceived brand image. Journal of Business Research 68(9): 1886-1894.

Nyadzayo, M.W., M.J. Matanda, and M.T. Ewing. 2016. Franchiseebased brand equity: The role of brand relationship quality and brand citizenship behavior. Industrial Marketing Management 52: $163-174$

Piehler, R., S. Hanisch, and C. Burmann. 2015. Internal brandingRelevance, management and challenges. Marketing Review St. Gallen 32(1): 52-60.

Piehler, R., C. King, C. Burmann, and L. Xiong. 2016. The importance of employee brand understanding, brand identification, and brand commitment in realizing brand citizenship behaviour. European Journal of Marketing 50(9/10): 1575-1601.

Porricelli, M.S., Y. Yurova, R. Abratt, and M. Bendixen. 2014. Antecedents of brand citizenship behavior in retailing. Journal of Retailing and Consumer Services 21(5): 745-752.

Powell, Shaun M. 2014. Twenty-one years of the journal of brand management: A commemorative review. Journal of Brand Management 21(9): 689-701.

Punjaisri, K., and A. Wilson. 2007. The role of internal branding in the delivery of employee brand promise. Journal of Brand Management 15(1): 57-70.

Punjaisri, K., and A. Wilson. 2011. Internal branding process: Key mechanisms, outcomes and moderating factors. European Journal of Marketing 45(9/10): 1521-1537.
Punjaisri, K., A. Wilson, and H. Evanschitzky. 2008. Exploring the influences of internal branding on employees' brand promise delivery: Implications for strengthening customer-brand relationships. Journal of Relationship Marketing 7(4): 407-424.

Punjaisri, K., H. Evanschitzky, and A. Wilson. 2009. Internal branding: An enabler of employees' brand-supporting behaviours. Journal of Service Management 20(2): 209-226.

Saleem, F.Z., and O. Iglesias. 2016. Mapping the domain of the fragmented field of internal branding. Journal of Product \& Brand Management 25(1): 43-57.

Shaari, H., S.M. Salleh, and Z. Hussin. 2011. Exploring the dimension of internal brand citizenship behavior in Malaysia. World Review of Business Research 1(1): 25-33.

Sirianni, N.J., M.J. Bitner, S.W. Brown, and N. Mandel. 2013. Branded service encounters: Strategically aligning employee behavior with the brand positioning. Journal of Marketing 77(6): 108-123.

Terglav, K., M. Konečnik Ruzzier, and R. Kaše. 2016. Internal branding process: Exploring the role of mediators in top management's leadership-commitment relationship. International Journal of Hospitality Management 54: 1-11.

Tuominen, S., S. Hirvonen, H. Reijonen, and T. Laukkanen. 2016. The internal branding process and financial performance in service companies: An examination of the required steps. Journal of Brand Management 23(3): 306-326.

Xiong, L., C. King, and R. Piehler. 2013. 'That's not my job': Exploring the employee perspective to becoming brand ambassadors. International Journal of Hospitality Management 35: 348-359.

Rico Piehler is a postdoctoral researcher and lecturer at the Chair of Innovative Brand Management, University of Bremen, Germany. His research focuses on brand management (esp. internal branding, employer branding, city branding, sport branding) and social media marketing. His articles have been published in the Journal of Brand Management and the European Journal of Marketing, among others.

Debra Grace is a Professor of Marketing at Griffith University, Australia. Her research interests lie in various areas such as, branding, consumer behaviour, marketing metrics, internal marketing, and franchising. She is well published in international journals such as Journal of Retailing, European Journal of Marketing, Journal of Service Research, Journal of Services Marketing, Journal of Brand Management, and many more.

Christoph Burmann is a Professor and Head of the Chair of Innovative Brand Management at the University of Bremen in Germany. His research focuses on brand management, marketoriented management, and strategic marketing. He is editor of the book series Innovative Brand Management and author of brand management and marketing textbooks. His articles have been published in the Journal of Business Research, Journal of Brand Management, Journal of Product \& Brand Management, and the European Journal of Marketing, among others. 